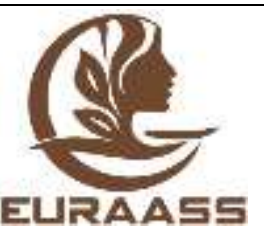

European Journal of GeOSCIENCES - Vol. 03 ISSUE 01 PP. 01-08 (2021)

European Academy of Applied and Social Sciences -

www.euraass.com

European Journal of Geosciences

OPEN $0^{\text {ACCESS }}$

https://www.euraass.com/ejgs/ejgs.html

Research Article

\title{
Monitoring Urban Expansion Using Remote-Sensing Data Aided by Google Earth Engine
}

\author{
Majid Aghlmand ${ }^{a}$, Gordana Kaplan ${ }^{\mathrm{b},}$ \\ ${ }^{a}$ Civil Engineering Department, Eskisehir Technical University, Eskisehir, Turkey. \\ ${ }^{b}$ Institute of Earth and Space Sciences, Eskisehir Technical University, Eskisehir, Turkey.
}

Received: 10 June 2020 / Revised: 10 January 2021 / Accepted: 15 January 2021

\begin{abstract}
Urbanization is accompanied by rapid social and economic development, while the process of urbanization causes the degradation of the natural ecology. Direct loss in vegetation biomass from areas with a high probability of urban expansion can contribute to the total emissions from tropical deforestation and land-use change. Monitoring of urban expansion is essential for more efficient urban planning, protecting the ecosystem and the environment. In this paper, we use remote sensing data aided by Google Earth Engine (GEE) to evaluate the urban expansion of the city of Isfahan in the last thirty years. Thus, in this paper we use Landsat satellite images from 1986 and 2019, integrated into GEE, implementing Support vector machine (SVM) classification method. The accuracy assessment for the classified images showed high accuracy (95-96\%), while the results showed a significant increase in the urban area of the city of Isfahan, occupying more than $70 \%$ of the study area. For future studies, we recommend a more detailed investigation about the city expansion and the negative impacts that may occur due to urban expansion.
\end{abstract}

Keywords: Remote Sensing; Google Earth Engine; Urbanization; Urban expansion; Isfahan.

(c) Euraass 2021. All rights reserved.

\section{Introduction}

In most parts of the world, rapid population growth in the last few decades has led to drastic urbanization. Although urbanization can be positive for some developing countries, it can affect negatively both the environment and human health. According to the United Nation, more than half of the population lives in urban areas, and by 2050 it is expected this number to increase to $65 \%$ (Fenta et al., 2017). The urban expansion in many areas affects not only local but global climate and environment as well. Direct loss in vegetation biomass from areas with a high probability of urban expansion is predicted to contribute about $5 \%$ of total emissions from tropical deforestation and land-use change (Seto et al., 2012). Urbanization is accompanied by rapid social and economic development, while the process of urbanization causes the degradation of the natural ecology. Many environmental problems have been demonstrated in the developed regions, such as change in land use type (Zhang et al., 2013), loss of biodiversity (Knapp et al., 2018; Križnik, 2018), deterioration of air quality (Lewis, 2018), increased heat island effect (Herath et al., 2018; Kaplan, 2019; Vuckovic et al., 2019), air

*Corresponding author: Email: kaplangorde@gmail.com (G. Kaplan).

Available online: 25 January 2021

DOI: https://doi.org/10.34154/2021-EJGS-0012/euraass

Journal reference: Eur. J. Geosc. 2021, 03(01), $01-08$.

ISSN-E: 2677-643X.

(C) European Academy of Applied and Social Sciences. Euraass - 2021. All rights reserved.

Cite as: Aghlmand, M., Kaplan, G. (2021). Monitoring Urban Expansion Using Remote-Sensing Data Aided by Google Earth Engine. Eur. J. Geosc. 03(01), 01 - 08. 
pollution (Mayer, 1999; Kampa and Castanas, 2008; Hou et al., 2019) and so on. Under this condition, the structure and function of the urban ecosystem have been destroyed, which seriously threatens the urban ecological and environmental security (Li et al., 2019).

Although the global urban area covers a small part of the world`s land surface, the rapid urban expansion in a different part of the world has led to drastic changes on other land use/land cover types. Monitoring of the urban expansion is essential for more efficient urban planning, protecting the ecosystem and the environment etc. Remote sensing has proven to be one efficient method for mapping and monitoring large scale areas using different approaches. One the biggest remote sensing advantages is the ability to classify the images into different classes. Fenta et al. (2017) used remote sensing data for monitoring the urban expansion and land cover changes in the city of Mekelle, Ethiopia. Their result showed significant urban expansion in the last 30 years. Mao et al. (2018) used remote sensing data for estimating wetland loss due to urban expansion and reported a double increase of the urban areas in twenty years, and also reported a huge loss of marsh wetlands. The urban expansion in Beijing has also been investigated using remote sensing data (Zhang et al., 2016). Their findings are then more than $50 \%$ of cultivated land has been converted to urban areas. With the rapid development of the cloud-based geospatial platform, Google Earth Engine (GEE), the number of studies investigating annual urban land mapping (Sengupta et al., 2019), cities classification (Agarwal and Nagendra, 2019) etc. have increased.

In this paper, the urban expansion of the third-largest city in Iran, the city of Isfahan for more than three decades, has been investigated using Landsat data in GEE. In this paper we use satellite images from 1986 and 2019, integrated into GEE. The main aim of this paper was to evaluate the urban expansion of the city of Isfahan and to estimate the loss of the green areas due to urban expansion.

\section{Material and methods}

\subsection{Study area}

The city of Isfahan is located in the central part of the Iranian plateau. Isfahan is $424 \mathrm{~km}$ away from Tehran that stretches between longitudes: $50^{\circ} 45^{\prime}$ and $51^{\circ} 34^{\prime}$ and latitude $33^{\circ} 10^{\prime}$ and $33^{\circ} 42^{\prime}$ (Fig 1.) The city of Isfahan is located on both sides of the Zayandehroud River. The Zayandehroud River divides Isfahan into northern and southern parts. The length of this river is $360 \mathrm{~km}$ and it is known as one of the largest rivers in the central plateau of Iran.

Isfahan was the capital of Iran from 1050 to 1722 AD and is considered to be a historical city, and many of Isfahan's historic buildings are listed as UNESCO World Heritage Sites. Isfahan was also selected in 2006 as the cultural capital of the Islamic world.

Table 1: Isfahan population in different years according to the National Statistics Organization (2011).

\begin{tabular}{ccc}
\hline Year & Population Isfahan & Isfahan province \\
\hline 1956 & 254.870 & - \\
1966 & 424.045 & - \\
1976 & 671.510 & -- \\
1986 & 986.753 & $3,294,916$ \\
1996 & 1.310 .659 & $3,923,255$ \\
2006 & 1.624 .838 & $4,559,256$ \\
2011 & 1.796 .967 & $4,879,312$ \\
2016 & 2.243 .249 & 5.120 .850 \\
\hline
\end{tabular}

According to the National Statistical Yearbook (2011), after Tehran and Mashhad, Isfahan is the third largest, most industrialized and populous city in Iran. The city of Isfahan has been under rapid urbanization over the past few decades, with population growth from 986,753 in 1986 , to $2,243,249$ in 2017 . The demographic information of different years of Isfahan city is presented in Table 1. 


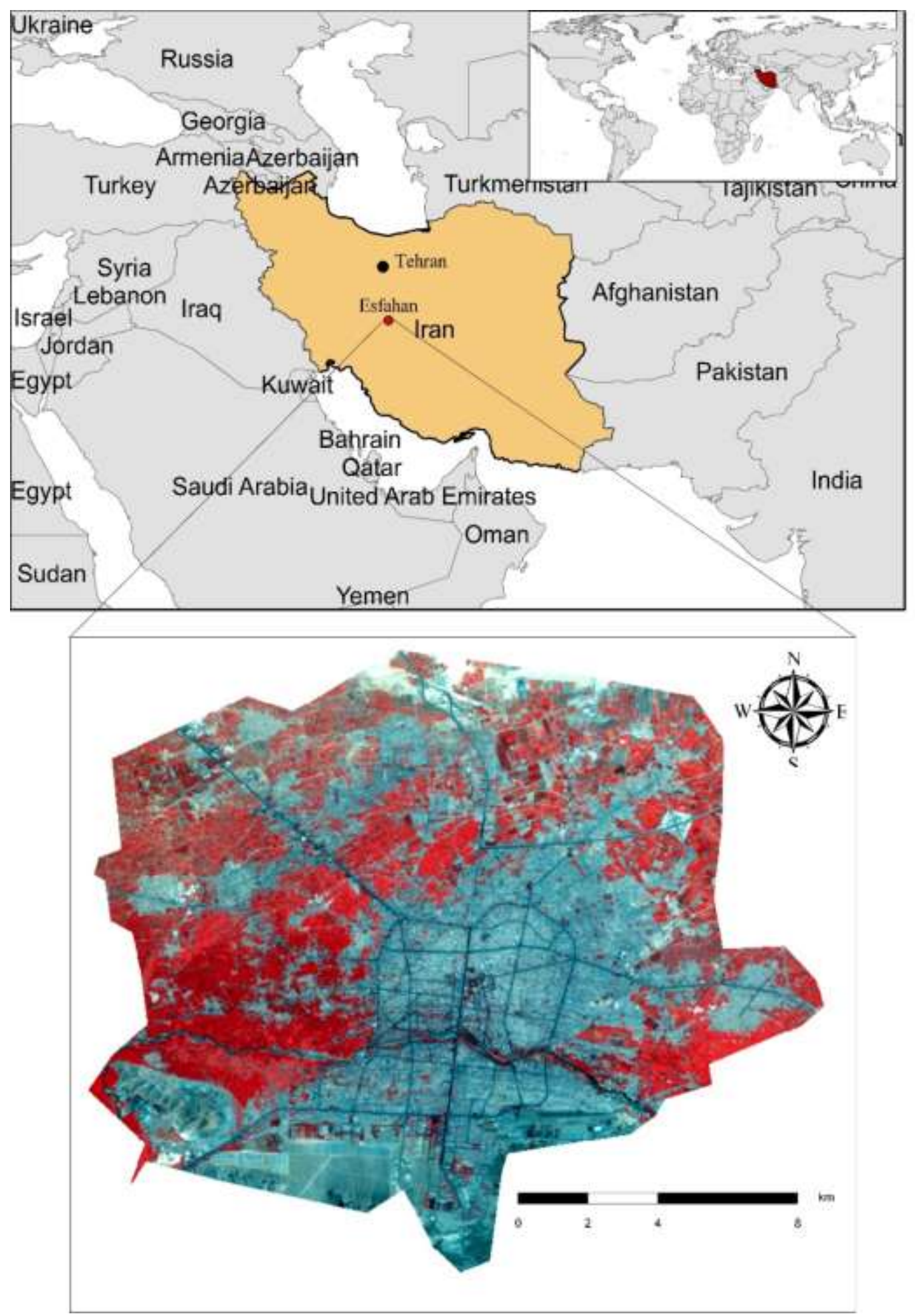




\subsection{Data and Methods}

GEE was used in this study (Gorelick et al., 2017). GEE is a cloud-based geospatial processing platform and can perform analyzes in a short time. All of the data integrated in GEE has an open-source. These data are from the last 40 years, which can be used to conduct data mining on a global scale. In addition to providing data, GEE provides powerful tools for analysis. GEE has been used in many studies mainly in forest and water coverage, land use changes or assess the health of agricultural fields, and more (Koskinenet al., 2019; Venkatappa et al., 2019; Wang et al., 2019).

The Landsat legacy data are available on GEE. In this study, Landsat data have been used. The information for each satellite is presented in Table 2. In this research, satellite images of Isfahan city were selected from the GEE database. These images are from 1986 and 2019. The 1986 images from Landsat 5 satellite, USGS Landsat 5 Surface Reflectance Tier 1, and the 2019 images from Landsat 8 satellite, USGS Landsat 8 Surface Reflectance Tier 1, were used. Landsat 5 images have been atmospherically corrected using LEDAPS, and include a cloud, shadow, water and snow mask produced using CFMASK, as well as a per-pixel saturation mask and Landsat 8 images have been atmospherically corrected using LaSRC and includes a cloud, shadow, water and snow mask produced using CFMASK, as well as a per-pixel saturation mask.

Table 2. Landsat datasets in the earth engine data catalog.

\begin{tabular}{lcccc}
\hline Dataset & Nominal resolution & Temporal granularity & Temporal coverage & $\begin{array}{c}\text { Spatial } \\
\text { coverage }\end{array}$ \\
\hline Landsat 8 OLI/TIRS & $30 \mathrm{~m}$ & 16 day & 2013 -Outgoing & Global \\
Landsat 7 ETM + & $30 \mathrm{~m}$ & 16 day & $2000-$ Outgoing & Global \\
Landsat 5 TM & $30 \mathrm{~m}$ & 16 day & $1984-2012$ & Global \\
\hline
\end{tabular}

In this study, the selected images from Landsat 5 were between 05/01/1986 and 10/01/1986 while Landsat 8 satellite images were acquired between 05/01/2019 and 01/01/2019. During this time, images have the lowest cloud content. Whit the use of the Median algorithm in GEE all clouds were removed from the images.

For all the selected images, besides the spectral bands, 4 indexes were also calculated; NDVI (Normalized difference vegetation index) (Hu et al., 2016), NDWI (Normalized Difference Water Index) (Li et al., 2013), NDBI (normalized difference built-up index) (Dammalage and Jayasinghe, 2019) and Urban Index (UI) (Table 3). Each index was calculated using the Maximum Valve Composite Algorithm. In this algorithm, based on pixels by pixels, each value of the index is examined and only the highest value for each pixel is considered.

Table 3: Information of the indexes considered in the research.

\begin{tabular}{lcc}
\hline Type & Index & Formula \\
\hline Vegetation index & NDVI & $\frac{N I R-R E D}{N I R+R E D}$ \\
\hline Water index & NDWI & $\frac{\text { Green }-N I R}{\text { Green }+N I R}$ \\
\hline Built-up index & NDBI & $\frac{S W I R 1-N I R}{S W I R 1+N I R}$ \\
\hline Urban Index & UI & $\frac{S W I R 2-N I R}{S W I R 2+N I R}$ \\
\hline
\end{tabular}

A variety of classification methods are integrated into GEE. SVM (Support vector machine) is one of these methods. The SVM algorithm is known as the best pixel-based classification algorithm (Poursanidis et al., 2015) and in the last decade, many studies have 
used SVM as a supervised non-parametric approach (Foody and Mathur, 2004; Pal and Mather, 2005) . In cases where we are limited by training data, SVM performs much better than other traditional classification algorithms such as ML (Maximum Likelihood). SVM conducts classification by determining hyperplanes that optimally separate classes (Park et al., 2018).

In this method, different classes are initially selected for classification. In this study five different classes have been determined; built-up, roads, green, barren and water. The number of training points per class used in the classifications is shown in Table 4.

Table 4. Class information and number of training data.

\begin{tabular}{ccc}
\hline No. & Class type & The training points \\
\hline 1 & Built-up & 330 \\
2 & Roads & 250 \\
3 & Green & 200 \\
4 & Barren & 160 \\
5 & Water & 160 \\
\hline
\end{tabular}

After preparing the layers for 1986 and 2019, the classification was done by SVM method. For the accuracy assessment in this study, we use the pixel-level error and confusion matrices. Besides the basic accuracy measure overall accuracy, the classification accuracy of the individual class can also be calculated using the user's and producer's accuracy. When it comes to selecting the number of samples used in the accuracy assessment, Banko (1998), suggested that 75-100 samples should be taken per class. Thus, we use 412 random points to evaluate the accuracy of the classification. As reference data used in the confusion matrices, the Landsat satellite images were used. However, for places that was hard to distinguish, as reference data high-resolution imagery (Google Earth) has been taken, where the image acquisition has occurred in the same season as the image used for the training sample collection.

\section{Results}

The classifications for the used images have been evaluated with the cofusion-matrix accuracy model. For that purpose, 412 random reference points have been used over higher resolution imagery. The results show satisfying high accuracy values, with an overall accuracy of $95-96 \%$. Detailed results of the accuracy assessment are presented in Table 5 and Table 6.

Table 5. Accuracy assessment for 1986 .

\begin{tabular}{|c|c|c|c|c|c|c|}
\hline 1986 & Built-up & Roads & Water & Bareland & Green area & User's Accuracy \\
\hline Built-up & 117 & 2 & 0 & 1 & 0 & 97.50 \\
\hline Roads & 8 & 63 & 0 & 0 & 0 & 88.73 \\
\hline Water & 0 & 3 & 57 & 0 & 0 & 95.00 \\
\hline Bareland & 2 & 1 & 0 & 58 & 0 & 95.08 \\
\hline Green area & 0 & 0 & 0 & 0 & 100 & 100.00 \\
\hline Producer's Accuracy & 92.13 & 91.30 & 100.00 & 98.31 & 100.00 & \\
\hline Overall accuracy & 0.96 & & & & & \\
\hline
\end{tabular}


Table 6. Accuracy assessment for 2020.

\begin{tabular}{l|cccccc}
\hline $\mathbf{2 0 1 9}$ & Built-up & Roads & Water & Bareland & Green area & User's Accuracy \\
\hline Built-up & 114 & 3 & 0 & 3 & 0 & 95.00 \\
Roads & 0 & 75 & 0 & 0 & 5 & 93.75 \\
Water & 0 & 3 & 77 & 0 & 0 & 96.25 \\
Bareland & 3 & 0 & 0 & 59 & 0 & 95.16 \\
Green area & 1 & 3 & 0 & 0 & 101 & 96.19 \\
Producer's Accuracy & $\mathbf{9 6 . 6 1}$ & $\mathbf{8 9 . 2 9}$ & $\mathbf{1 0 0 . 0 0}$ & $\mathbf{9 5 . 1 6}$ & $\mathbf{9 5 . 2 8}$ & \\
Overall accuracy & $\mathbf{0 . 9 5}$ & & & & & \\
\hline
\end{tabular}
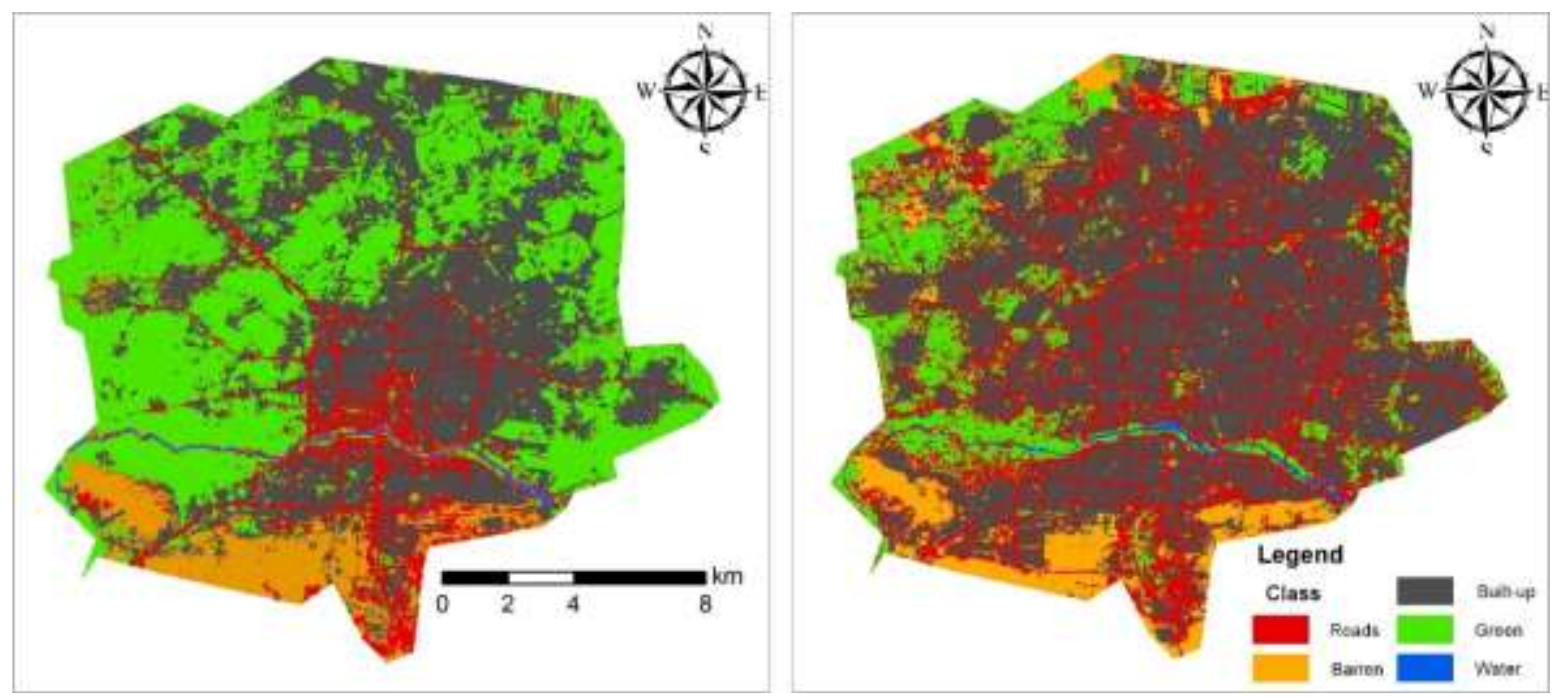

Figure 2: Classification results (left - 1986; right - 2019).

Table 7. Land conversion between 1986 and 2019.

\begin{tabular}{|c|c|c|c|c|c|c|c|}
\hline & Roads & Barren Land & Built-up & Green & Water & Total \\
\hline & & \multicolumn{6}{|c|}{1986} \\
\hline Roads & \multirow{6}{*}{$\frac{\infty}{\circ}$} & 1249.8 & 349.3 & 2007.1 & 2228.5 & 9.4 & 5844.0 \\
\hline Barren Land & & 246.8 & 1052.9 & 517.7 & 460.4 & 2.9 & 2280.8 \\
\hline Built-up & & 666.7 & 592.3 & 6934.5 & 4604.8 & 0.6 & 12799.0 \\
\hline Green & & 99.0 & 118.8 & 372.5 & 3013.7 & 4.1 & 3608.1 \\
\hline Water & & 42.8 & 1.7 & 4.7 & 11.8 & 80.7 & 141.6 \\
\hline Total & & 2305.1 & 2115.0 & 9836.5 & 10319.1 & 97.7 & 24673.4 \\
\hline
\end{tabular}

The results of the analyses are presented in Figure 2. As it can be seen from the Figure, the urban area of the city of Isfahan has drastically developed over the years. The built-up areas mainly developed in the north and north-east part of the city, occupying large spaces of green areas. The results of the land cover change are presented in Table 7.

As it can be seen from Table 7, more than 4.600 ha of green areas have been transformed into an urbanized area, significantly lowering the green area for more $65 \%$, from 10.319 ha to 3.608 ha. Together with roads, the built-up area covers more than $70 \%$ of the study area. 


\section{Discussion and Conclusion}

From the analyses conducted in this study investigating the urban expansion of the third biggest city of Iran, Isfahan, it can be seen that the city has been drastically expanded over the last thirty years, leaving a small green space in the urban surroundings. The city of Isfahan is covered with more than $70 \%$ urban areas. This can lead to serious negative environmental impacts. Recent studies have shown that in order to stop urban heat island effects, $60 \%$ of the city needs to be covered with green area (Kaplan, 2019).

The study has also proven that GEE is a powerful tool for remote sensing image classification, achieving 96\% accuracy in this study. For future studies, we recommend a more detailed investigation of the urban expansion of the city of Isfahan, including more satellite images from different years. Also, since the urban area covers a large part of the city, the presence of urban heat islands is probable, and we recommend investigating changes in the city temperature of the years related to the urban expansion.

\section{References}

Agarwal, S. and H. Nagendra (2019). Classification of Indian cities using Google Earth Engine. Journal of Land Use Science 14(4-6): 425-439.

Banko, G. (1998). A review of assessing the accuracy of classifications of remotely sensed data and of methods including remote sensing data in forest inventory.

Dammalage, T. and N. Jayasinghe (2019). Land-Use Change and Its Impact on Urban Flooding: A Case Study on Colombo District Flood on May 2016. Eng. Technol. Appl. Sci. Res 9: 3887-3891.

Fenta, A. A., H. Yasuda, N. Haregeweyn, A. S. Belay, Z. Hadush, M. A. Gebremedhin and G. Mekonnen (2017). The dynamics of urban expansion and land use/land cover changes using remote sensing and spatial metrics: the case of Mekelle City of northern Ethiopia. International journal of remote sensing 38(14): 4107-4129.

Foody, G. M. and A. Mathur (2004). Toward intelligent training of supervised image classifications: directing training data acquisition for SVM classification. Remote Sensing of Environment 93(1-2): 107-117.

Gorelick, N., M. Hancher, M. Dixon, S. Ilyushchenko, D. Thau and R. Moore (2017). Google Earth Engine: Planetary-scale geospatial analysis for everyone. Remote sensing of Environment 202: 18-27.

Herath, H., R. Halwatura and G. Jayasinghe (2018). Evaluation of green infrastructure effects on tropical Sri Lankan urban context as an urban heat island adaptation strategy. Urban Forestry \& Urban Greening 29: 212-222.

Hou, Y., L. Wang, Y. Zhou, S. Wang, W. Liu and J. Zhu (2019). Analysis of the tropospheric column nitrogen dioxide over China based on satellite observations during 2008-2017."Atmospheric Pollution Research 10(2): 651-655.

Hu, T., J. Yang, X. Li and P. Gong (2016). Mapping urban land use by using landsat images and open social data. Remote Sensing 8(2): 151.

Kampa, M. and E. Castanas (2008). Human health effects of air pollution. Environmental pollution 151(2): 362-367.

Kaplan, G. (2019). Evaluating the roles of green and built-up areas in reducing a surface urban heat island using remote sensing data. Urbani izziv 30(2): 105-112.

Knapp, S., D. Haase, S. Klotz and N. Schwarz (2018). Do Urban Biodiversity and Urban Ecosystem Services Go Hand in Hand, or Do We Just Hope It Is That Easy? Urban Transformations, Springer: 301-312.

Koskinen, J., U. Leinonen, A. Vollrath, A. Ortmann, E. Lindquist, R. d'Annunzio, A. Pekkarinen and N. Käyhkö (2019). Participatory mapping of forest plantations with Open Foris and Google Earth Engine. ISPRS Journal of Photogrammetry and Remote Sensing 148: 63-74.

Križnik, B. (2018). Transformation of deprived urban areas and social sustainability: A comparative study of urban regeneration and urban redevelopment in Barcelona and Seoul. Urbani izziv 29(1): 83-95.

Lewis, A. C. (2018). The changing face of urban air pollution. Science 359(6377): 744-745.

Li, W., Z. Du, F. Ling, D. Zhou, H. Wang, Y. Gui, B. Sun and X. Zhang (2013). A comparison of land surface water mapping using the normalized difference water index from TM, ETM+ and ALI. Remote Sensing 5(11): 5530-5549.

Li, Z.-T., M.-J. Yuan, M.-M. Hu, Y.-F. Wang and B.-C. Xia (2019). Evaluation of ecological security and influencing factors analysis based on robustness analysis and the BP-DEMALTE model: A case study of the Pearl River Delta urban agglomeration. Ecological Indicators 101: 595-602.

Mao, D., Z. Wang, J. Wu, B. Wu, Y. Zeng, K. Song, K. Yi and L. Luo (2018). China's wetlands loss to urban expansion. Land degradation \& development 29(8): 2644-2657.

Mayer, H. (1999). Air pollution in cities. Atmospheric environment 33(24-25): 4029-4037.

$\mathrm{Pal}, \mathrm{M}$. and P. Mather (2005). Support vector machines for classification in remote sensing. International journal of remote sensing 26(5): 1007-1011.

Park, S., J. Im, S. Park, C. Yoo, H. Han and J. Rhee (2018). Classification and mapping of paddy rice by combining Landsat and SAR time series data. Remote Sensing 10(3): 447.

Poursanidis, D., N. Chrysoulakis and Z. Mitraka (2015). Landsat 8 vs. Landsat 5: A comparison based on urban and peri-urban land cover mapping. International Journal of Applied Earth Observation and Geoinformation 35: 259-269.

Sengupta, D., R. Chen, M. E. Meadows, Y. R. Choi, A. Banerjee and X. Zilong (2019). Mapping Trajectories of Coastal Land Reclamation in Nine Deltaic Megacities using Google Earth Engine. Remote Sensing 11(22): 2621.

Seto, K. C., B. Güneralp and L. R. Hutyra (2012). Global forecasts of urban expansion to 2030 and direct impacts on biodiversity and carbon pools. Proceedings of the National Academy of Sciences 109(40): 16083-16088. 
Venkatappa, M., N. Sasaki, R. P. Shrestha, N. K. Tripathi and H.-O. Ma (2019). Determination of vegetation thresholds for assessing land use and land use changes in Cambodia using the Google Earth Engine cloud-computing platform. Remote Sensing 11(13): 1514.

Vuckovic, M., W. Loibl, T. Tötzer and R. Stollnberger (2019). Potential of Urban Densification to Mitigate the Effects of Heat Island in Vienna, Austria. Environments 6(7): 82.

Wang, Y., J. Ma, X. Xiao, X. Wang, S. Dai and B. Zhao (2019). Long-Term Dynamic of Poyang Lake Surface Water: A Mapping Work Based on the Google Earth Engine Cloud Platform. Remote Sensing 11(3): 313.

Zhang, C., J. Wu, N. B. Grimm, M. McHale and A. Buyantuyev (2013). A hierarchical patch mosaic ecosystem model for urban landscapes: model development and evaluation. Ecological modelling 250: 81-100.

Zhang, Z., N. Li, X. Wang, F. Liu and L. Yang (2016). A comparative study of urban expansion in Beijing, Tianjin and Tangshan from the 1970s to 2013. Remote Sensing 8(6): 496. 